\title{
Tecnología y simbolismo en la cestería ashaninka
}

Artículos originales: ANTROPOLOGÍA

Recibido: 17/02/2021

Aprobado: 12/06/2021

Publicado: 14/10/2021

\author{
Enrique Carlos Rojas Zolezzi \\ Universidad Nacional Mayor de San Marcos \\ erojasz@unmsm.edu.pe
}

\section{RESUMEN}

El presente artículo muestra el lugar de los conocimientos técnicos y etnobotánicos, así como los aspectos estéticos y simbólicos vinculados a la cestería en la construcción de las bases materiales de la división del trabajo según género en la sociedad ashaninka (arawak pre-andinos) del oriente peruano.

Palabras clave: Amazonía, ashaninka, tecnología, expresiones estéticas, simbolismo, género.

\section{Technology and symbolism in ashaninka basketry}

\section{ABSTRACT}

This article explains the role of technological and ethnobotanical knowledge, the aesthetic and symbolic aspects of basketwork in creating the material basis of the gender division of labor among the ashaninka on the Peruvian Amazon.

KEYwORDs: Amazonia, ashaninka, technology, aesthetic expression, symbolism, gender. 


\section{Introducción}

A menudo minusvaloradas por la cultura occidental desde su reemplazo por los objetos producidos en cerámica, vidrio, metales y recientemente plástico, las técnicas de cestería siguen jugando aún hoy en las sociedades de horticultores-cazadores-recolectores un papel central en la dinámica social (Lévi-Strauss 1993). Para el caso de la Amazonía sudamericana éstas han sido generalmente incluidas en los estudios etnográficos desde el siglo XIX dentro de la amplia categoría de «cultura material» la que nace del período de desarrollo de la antropología vinculado a la formación de los museos etnográficos entendidos entonces como meros repositorios de los vestigios tangibles de las sociedades con las que tropezaba el mercado mundial en su avance arrollador. Diferentes etnógrafos del área amazónica desde diferentes escuelas han tratado posteriormente de ir más allá de este acercamiento superficial buscando entender dichos objetos como resultado de la aplicación cotidiana del conjunto de conocimientos etnobotánicos y técnicos acumulados por las poblaciones que los producen y a partir de los cuales una determinada población interacciona con la materia y los seres vivientes de su entorno así como ubicando las reglas de su uso dentro de la división del trabajo por género y edad, muchas veces vinculados a aspectos simbólicos, al igual que las variaciones estacionales del tiempo dedicado a su producción, en suma, como parte de la dinámica de reproducción material y social de este tipo de sociedad.

En la cuenca amazónica este tipo de investigaciones permitieron llegar a finales de los años 1940 en base a la información acumulada hasta entonces a síntesis que no podían llevar más allá de una gruesa clasificación de las técnicas de entrelazado, una cierta distribución espacial de éstas, una imprecisa ubicación dentro de la división sexual del trabajo, y la identificación de algunos de los materiales empleados (O’Neale 1949). Posteriormente, estas investigaciones, iniciadas por etnógrafos de la talla de KochGrünberg (1910/2011), Roth (1921), Nordenskiöld y Schlosser (1924), Farabee (1922, 1924), Métraux (1928) y Tessmann (1930/1999) entre otros, serían retomadas desde las perspectivas más productivas señaladas por ejemplo por autores como Lizot (1974) y Hames y Hames (1976). Si bien en las monografías etnográficas de las últimas décadas la referencia a estas tecnologías ha recaído en breves referencias intercaladas a título ilustrativo al lado de preocupaciones centradas en los aspectos simbólicos de los sistemas sociales de las poblaciones señaladas pensamos que es pertinente su registro y estudio como parte de la dinámica social de reproducción material y de las relaciones sociales en este tipo de poblaciones (Godelier 1984). Asimismo, Lévi-Strauss recuperando informaciones de las etnografías clásicas, nos recuerda que, a lo largo del espacio americano, a objetos manufacturados, de los que los productos de las técnicas de la cestería forman parte, se les atribuyen espíritus (Lévi-Strauss 1993: 160-167) aspecto que nos permite profundizar en la comprensión del contexto de relaciones sociales en que son producidos.

En el presente texto nos ocuparemos de las técnicas de cestería de los ashaninka (arawak pre-andinos) del piedemonte oriental de los andes centrales, basándonos en el registro de las técnicas de producción y conocimientos implicados así como en las reglas que definen la separación por género y edad de su utilización, y los personajes vinculados a dichos objetos en la mitología, trabajo que ha ocupado diferentes etapas de nuestras visitas a esta población de horticultores-cazadores-recolectores organizada en parentelas cognáticas y una regla de residencia postmatrimonial uxorilocal que se iniciaran hacia 1986 (Rojas Zolezzi 1990, 1994).

Abordaremos aquí tanto los conocimientos empleados en su producción y uso como los aspectos simbólicos de éstos en cuanto que todos ellos forman parte de la construcción de los géneros, especialmente el femenino, en esta población. Este trabajo tiene, por otra parte, como objeto, complementar, dentro de nuestro análisis de las bases de conocimientos tecnológicos y ecológicos del género femenino entre los ashaninka, aquel que publicáramos anteriormente acerca de los telares empleados por las mujeres en este grupo (Rojas Zolezzi, E. 1999). Los reportes anteriores acerca de la cestería ashaninka se reducen a simples relaciones incompletas de nombres de objetos y muy someras descripciones (Craig 1967, Weiss 1975: 534; Weiss 2005: 20; 2005:20). Otros autores han incorporado en sus análisis de los aspectos simbólicos de las culturas de los cercanamente emparentados matsiguengas (Baer 1994; Rojas Zolezzi, M. 2017) referencias a este tipo de técnicas. 


\section{Conceptos y métodos empleados}

Como señalara Leroi-Gourhan si bien el tejido de telas y la cestería pueden ser entendidas como subdivisiones de una clase general que son los tejidos, el que comprende "todas las formas de ensamblaje de dos capas de elementos paralelos» (nuestra traducción), distinguiendo el primero del segundo la utilización de un cuadro de tensión o suspensión de los hilos independientemente del modo en que son intrincados dichos elementos, siendo esto posible en el caso de la cestería por la rigidez de los elementos independientemente de la forma que tome el entrelazamiento (Leroi-Gourhan 1971:269).

Para el caso de la cestería, la primera capa recibe el nombre de montantes y la segunda de hebras (brins en el original francés). La primera capa (los montantes) es pasiva y compuesta de elementos fijos y la segunda capa (las hebras) móvil (Leroi-Gourhan 1971: 245). Posteriormente, aportando al análisis de las funciones de los elementos en juego, Balfet señalaría que los montantes constituirían un armazón (charpente en el original, nuestra traducción) los que tendrían por función dar la rigidez y la forma general a la cesta conservando el término de hebras para los elementos flexibles los que tendrían por función mantener juntos a los montantes. Recientemente esta misma autora reconoce una tercera dimensión, que

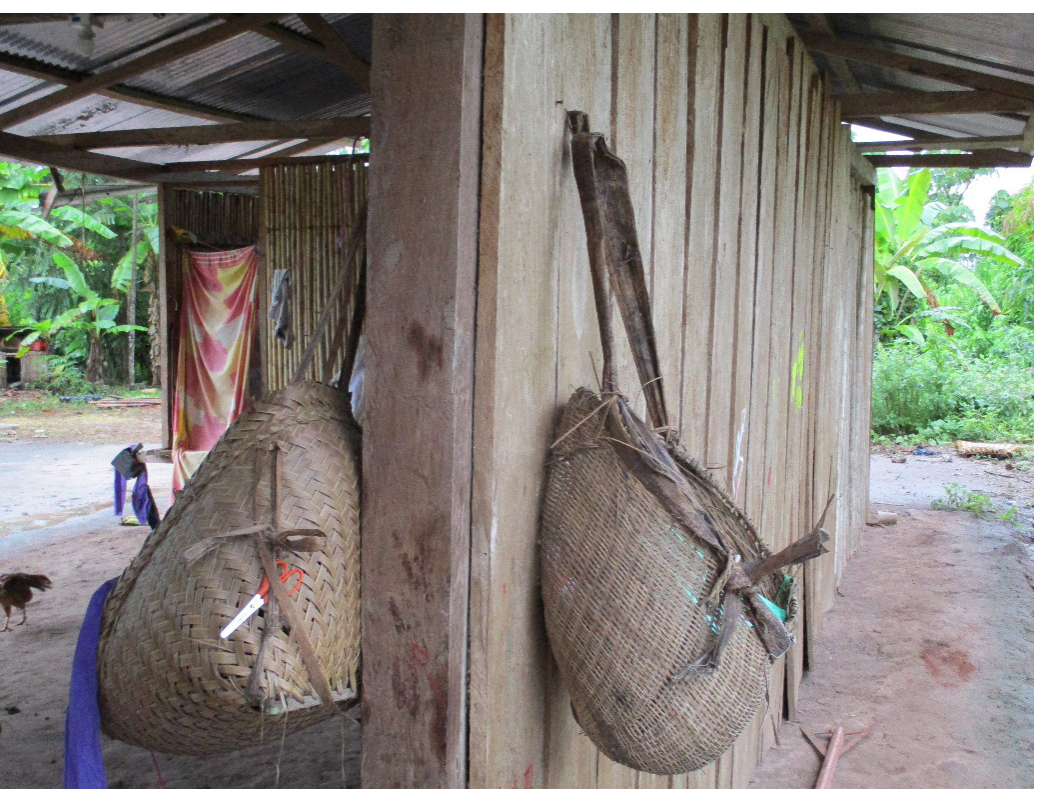

Fig 1. Canastas de carga frontal kantsiri (derecha) y kamiante 0 tsimiante (izquierda) permite un mayor acercamiento a la interpretación histórica y cultural de la cestería, indisociable de su proceso de producción, aquel de los modos de expresión estética, estrechamente vinculados a los modos de reunión de los elementos, de la que depende el reconocimiento de su valor estético tanto por parte de sus productores como de sus usuarios (Balfet 1993).

Sin embargo, como ya Lévi-Strauss había señalado por entonces, además de los aspectos decorativos, en muchas culturas amerindias, tienen expresión en estos objetos, imperativos de otro orden: fallas técnicas intencionalmente cometidas en el entrelazamiento de las cestas, las que constituyen "puertas» por donde escapan los espíritus que residen en ellas durante el efímero periodo útil de éstas cuando son desechadas (Lévi-Strauss 1993: 161, nuestra traducción). En esta exposición ordenaremos las diferentes técnicas de cestería de acuerdo a las funciones principales que le son asignadas y analizaremos a través de la mitología ashaninka los aspectos simbólicos vinculados a ella.

\section{Técnicas de cestería vinculadas a las necesidades de transporte}

Las mujeres ashaninka producen y utilizan dos tipos de cesta que tienen por función principal el transporte de porte frontal de los alimentos cosechados del huerto, los frutos recogidos del bosque y los peces y camarones atrapados con piscícidas así como la leña a la casa. Una es la kantsiri, de fibras de la liana $t a-$ petsa o tsirompita (Asplundia sp.), tamishi en español regional, la que tiene mayor difusión, y la kamiante (Kindberg 1980:303) o tsimianti (Weiss 1975:534), de hoja de la palmera kompiroshi (Phytelephas), yarina en español regional, producida por razones ecológicas únicamente en el valle del río Ene en la que escasea la liana señalada (figura 1).

Las lianas tapetsa con la que las mujeres adultas producen la canasta kantsiri (fig. 2) se desarrollan en colonias (tapetsamashi) en zonas en que la densidad de árboles es menor en el bosque primario creciendo apoyadas a éstos. La liana es recolectada por la mujer cogiéndola con ambas manos por el tallo y separada del árbol en el que se apoya con un fuerte movimiento hacia abajo, pues de lo contrario, ella ofrece una considerable resistencia que hace imposible retirarla 


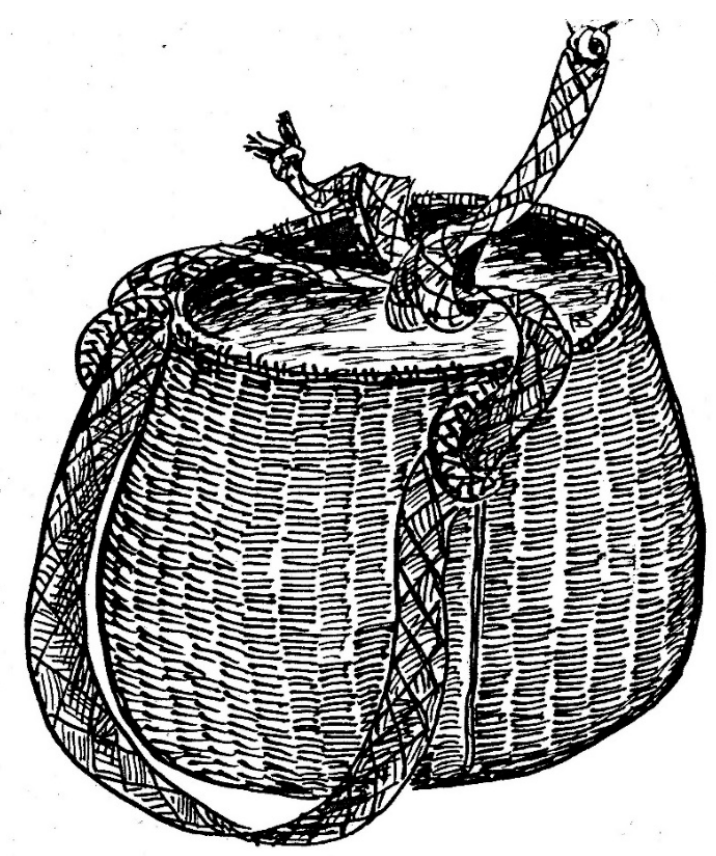

Fig.2 Canasta de carga kantsiri

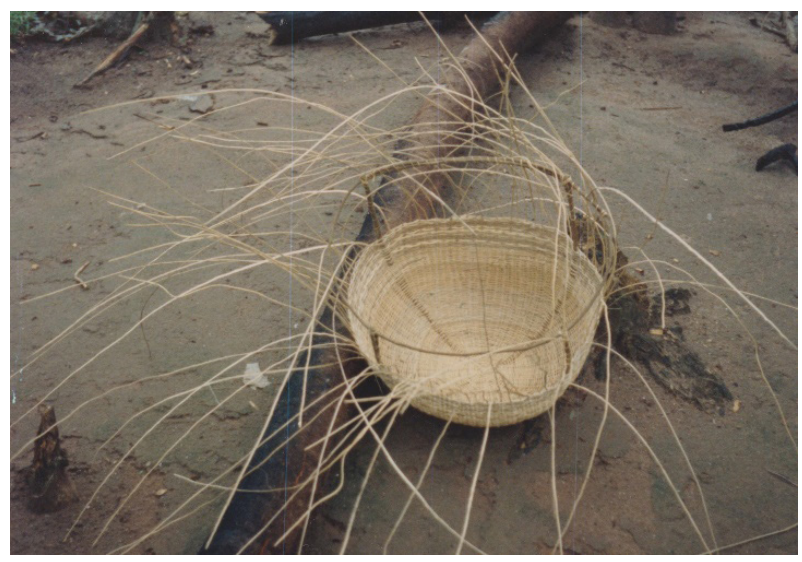

Fig. 4. Detalle de la estructura y el tejido del fondo de la canasta kantsiri

del lugar donde se ha desarrollado. Desde este lugar este material es transportado en grandes rollos a las casas por aquellas donde serán descortezadas y divididas en fibras introduciendo las uñas en el extremo o con el filo de una lámina de metal. La cesta kantsiri puede ser descrita como de forma semiesférica, de tejido de tipo recto de hebras tejidas, de armado de tipo una toma otra salta (1/1). Este es realizado sobre un armazón de secciones de la misma liana sin descortezar ni divididas en fibras. Dicho armazón está constituido por dos secciones que se cruzan para formar la base cuyos extremos se unen en puntos opuestos a un amplio anillo (figura 4) Un haz de hebras se cruzan en dicho punto central de cruce para formar el

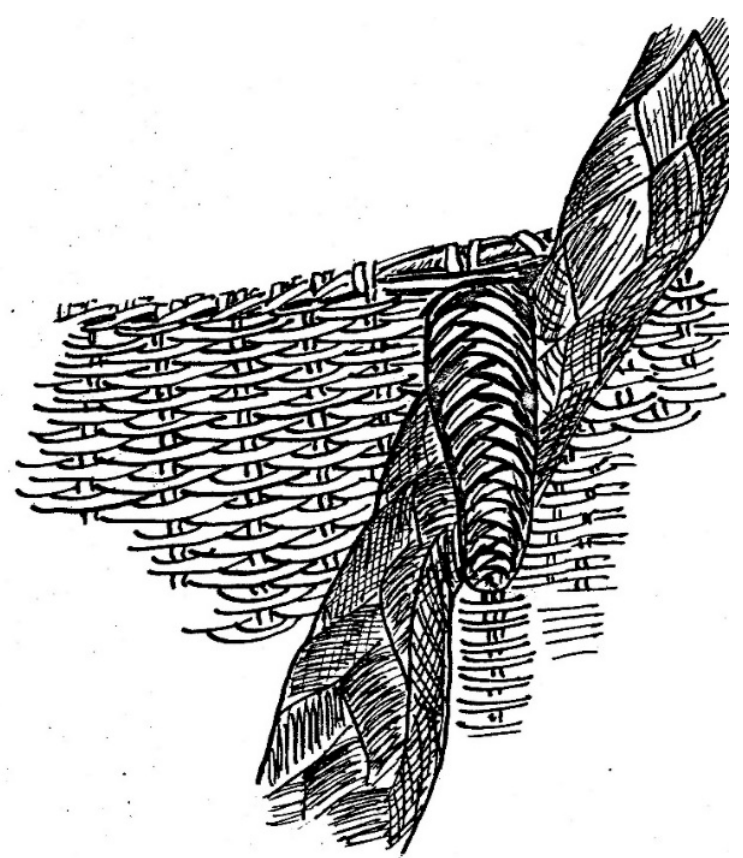

Fig. 3 Detalle del borde, asas y correa

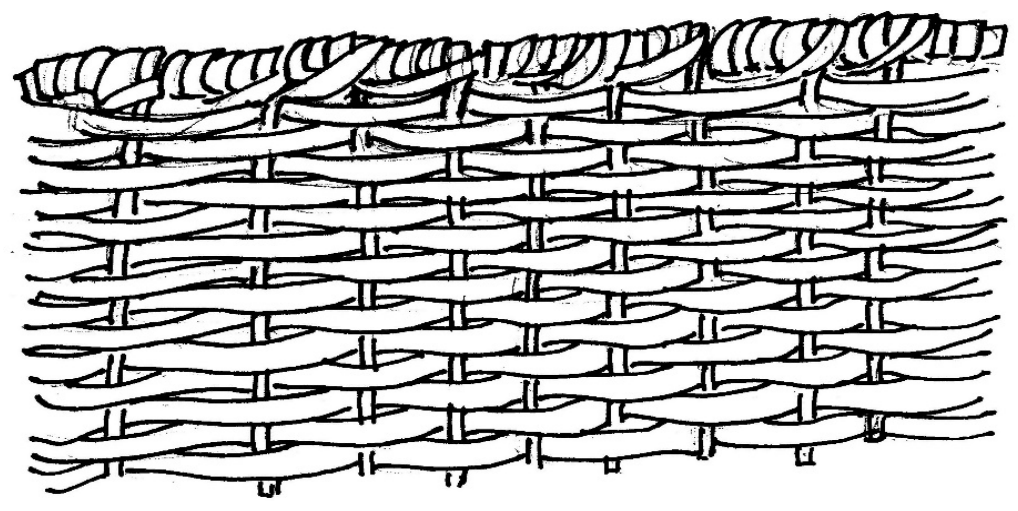

Fig. 5 Kantsiri. Tejido 1/1

conjunto de los montantes. Desde este mismo punto se da forma a la base con una hebra que parte en trayectoria circular entrelazándose entre los montantes desde el fondo de la cesta hasta su borde con tejido una tomada una saltada. Los montantes, son enrollados en este mismo borde y el extremo final introducido en el tejido en sentido inverso, es decir, hacia abajo, por la parte externa de la cesta. Le pueden ser añadidas dos asas en forma de trenzas (figura 3) de un tejido trenzado llamado shoyó o se le pueden amarrar cuatro tiras de tela introducidas entre el tejido cerca al borde que forman también asas. Por estas, son introducidas una correa tejida o simplemente una banda, hechas de la corteza interior de los árboles 


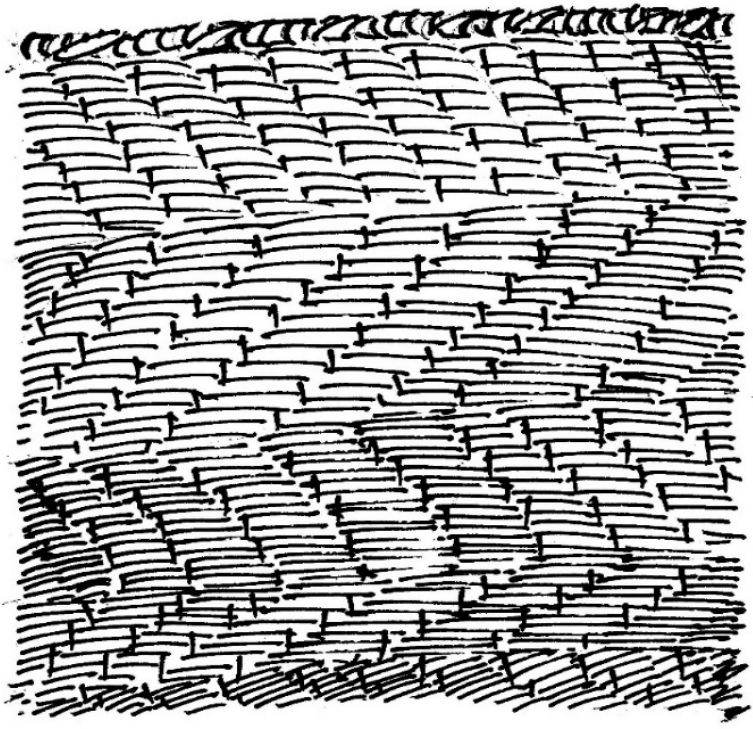

Fig. 6 Kantsiri. Tejido 2/2 kanínari

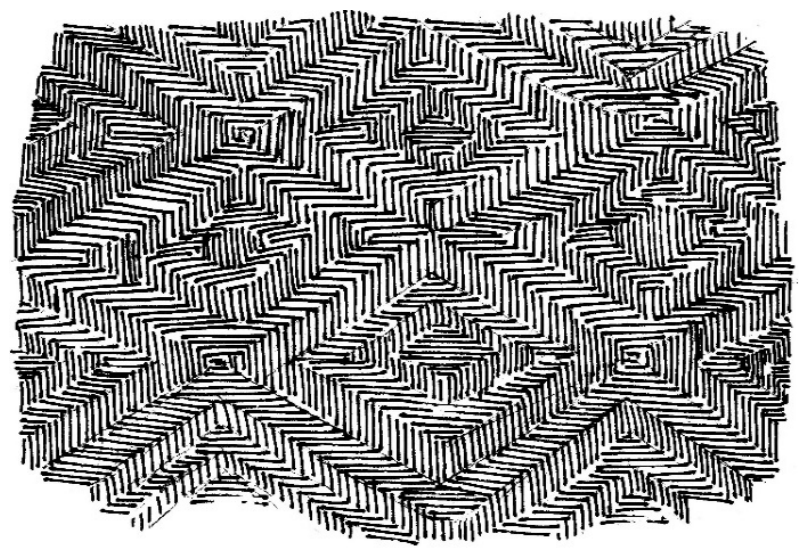

Fig.7 Kantsiri. Tejido 3/3 ponkaro

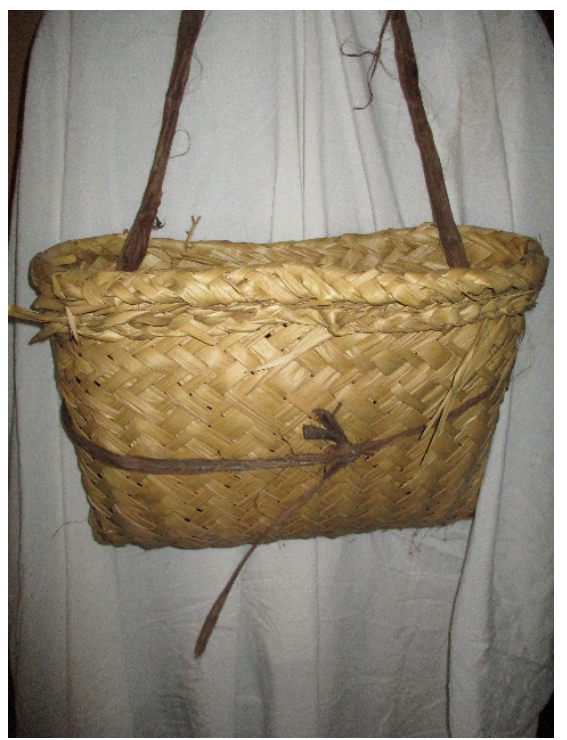

Fig. 8 kamiante de palma yarina (Phytelefas). Detalles. llamados shiwitsa o shiwitha correspondientes a la familia Annonaceae, Guatteria chlorantha y Annona sp. (Reynel et al. 1990: 64-65) para transporte de porte frontal. La forma básica presenta un tejido de una tomada una saltada $1 / 1$, siendo también tejida en $2 / 2$, tejido llamado kaninari (ver figura 3) y $3 / 3$ ponkaro que representa el pico del loro (ver figuras 5, 6 y 7 ).

La canasta para carga frontal kamiante por su parte (figuras 1 derecha y 8 ) tiene por base el raquis de la hoja de palmera de la cual es confeccionada en su parte central. Este es obtenido por el hijo de la tejedora con ayuda de un machete quien es el encargado de trepar hasta la corona de la palma. El peciolo y la punta de la hoja son cortados con un machete, siendo entrelazados los foliolos de los extremos restantes en tejido una tomada una saltada para dar forma tanto a los extremos como a las paredes del recipiente que constituye este tipo de cesto. El borde es resuelto trenzando los extremos de los foliolos. Una banda es tejida con los foliolos restantes obtenidos de haber cortado los extremos de la hoja y colocada alrededor del borde del cesto atando sus extremos con un nudo plano a fin de evitar que el tejido de la canasta se deshaga. En este caso la banda de porte frontal hecha de la corteza interior de los árboles ya señalados sostiene la base de la canasta constituida por el raquis de la hoja de palma y atraviesa las paredes de la canasta en dos puntos cercanos a la trenza que refuerza la canasta en el borde para unirse en el extremo con un nudo plano.

\section{Cestería vinculada a la transformación y conservación de los alimentos}

\section{Coladores}

El tsikamentotsi, literalmente objeto para colar, es producido tanto de fibras de la liana tapetsa o tsirompitha (figura 9) como de la fibra obtenida del raquis de la palma tiroti (Astrocaryum) llamada en español regional huicungo (figura 10) y es utilizado para separar el líquido de la masa de pulpa de yuca hervida, machacada, masticada y escupida por las mujeres y dejada fermentar en el recipiente tallado en el tronco de un árbol en forma de una canoa pequeña inchátona o en el tronco ahuecado kahoni (del español caja) al momento de consumir la bebida de yuca fermen- 

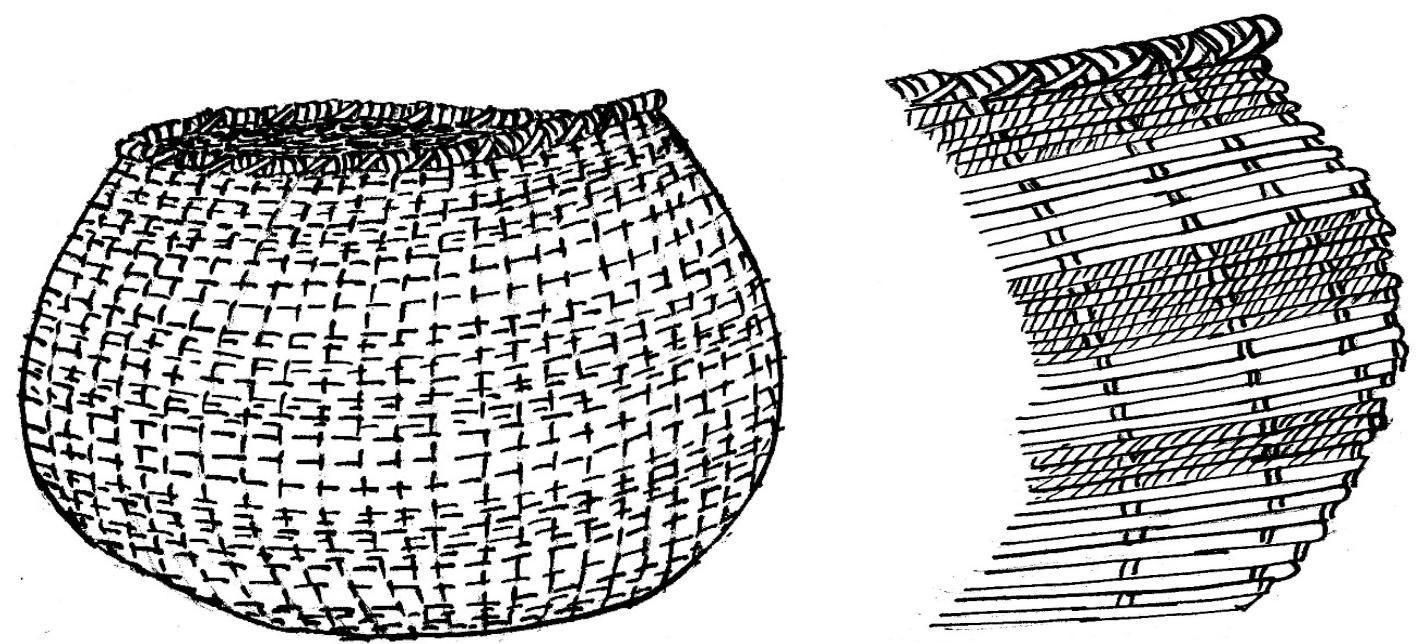

Fig. 9. Colador y detalle del borde y la pared

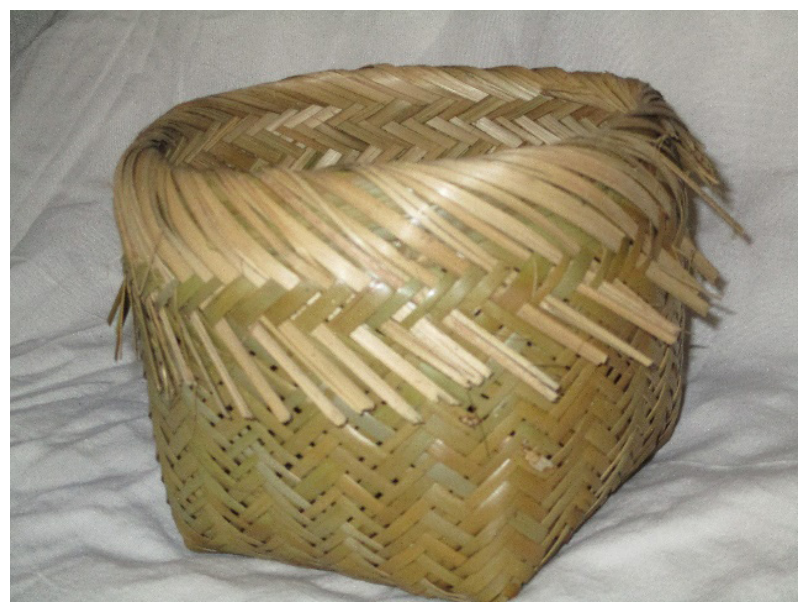

Fig. 10 Colador de fibra del raquis de la palma tiroti.

tada piarentsi. En su primera forma es producido a la a la manera de una cesta kantsiri en una versión más pequeña, aunque sin estructura exterior, de tejido $1 / 1$. La segunda forma presenta un tejido $3 / 3$ que se inicia en el fondo. El borde se logra doblando por el reverso los montantes hacia abajo e introduciendo sus extremos en la parte exterior del tejido a una misma altura. En ambos tipos, este utensilio es producido por la mujer con la sola ayuda de un cuchillo.

\section{Abanicos para avivar el fuego}

Si los instrumentos para producir fuego, han sido ya reemplazados por los fósforos, medio indispensable en la actividad de transformación de los alimentos y producción de algunos utensilios para la activación del fuego, es el hewárontsi o abanico, término que abarca aquellos elaborados mediante la unión de plumas como con técnicas de cestería. Estos son tejidos

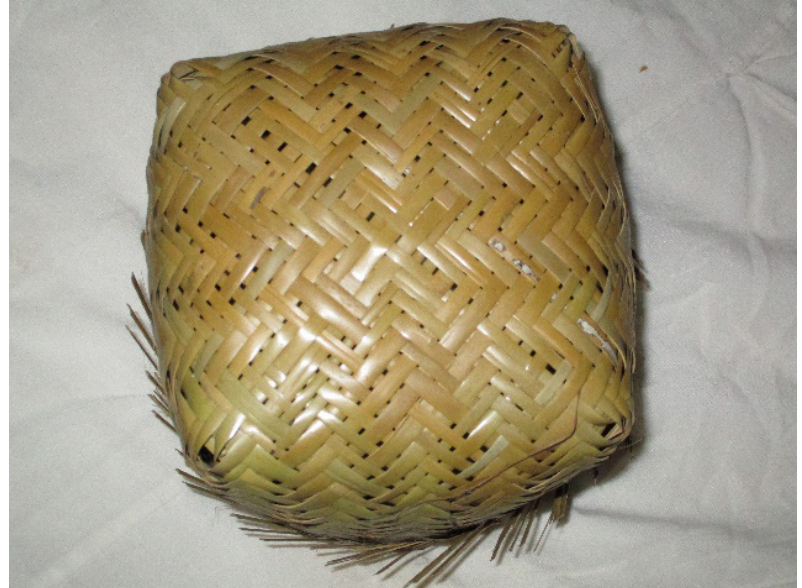

Fig.11 Detalle del fondo.

con los foliolos obtenidos de la fronda de la ya citada palmera tiroti (Astrocaryum sp.). por el hijo de la tejedora con el machete y secados bajo la sombra del techo de la casa sobre esteras. El tejido de los hewárontsi puede ser llevado a cabo en diferentes formas. En las figuras 12 y 13 son ejemplificados respectivamente los tipos de tejido katsiatonkiri y etsipeki (que alude al diseño del caparazón del armadillo etsí (Dassipus kappleri), que constituyen sargas. Estos, junto con el abanico de plumas anteriormente reportado por Tessmann (1930) son producidos por las mujeres.

\section{Conservación de alimentos}

La cesta tsimenkorentsi (fig. 14) es utilizada para guardar suspendidas de las vigas de las casas las carnes ahumadas o saladas de las presas o el pescado salado o ahumado envuelto en hojas. Este tipo de cesta es producida por la mujer. El tsimenkorentsi consiste en 

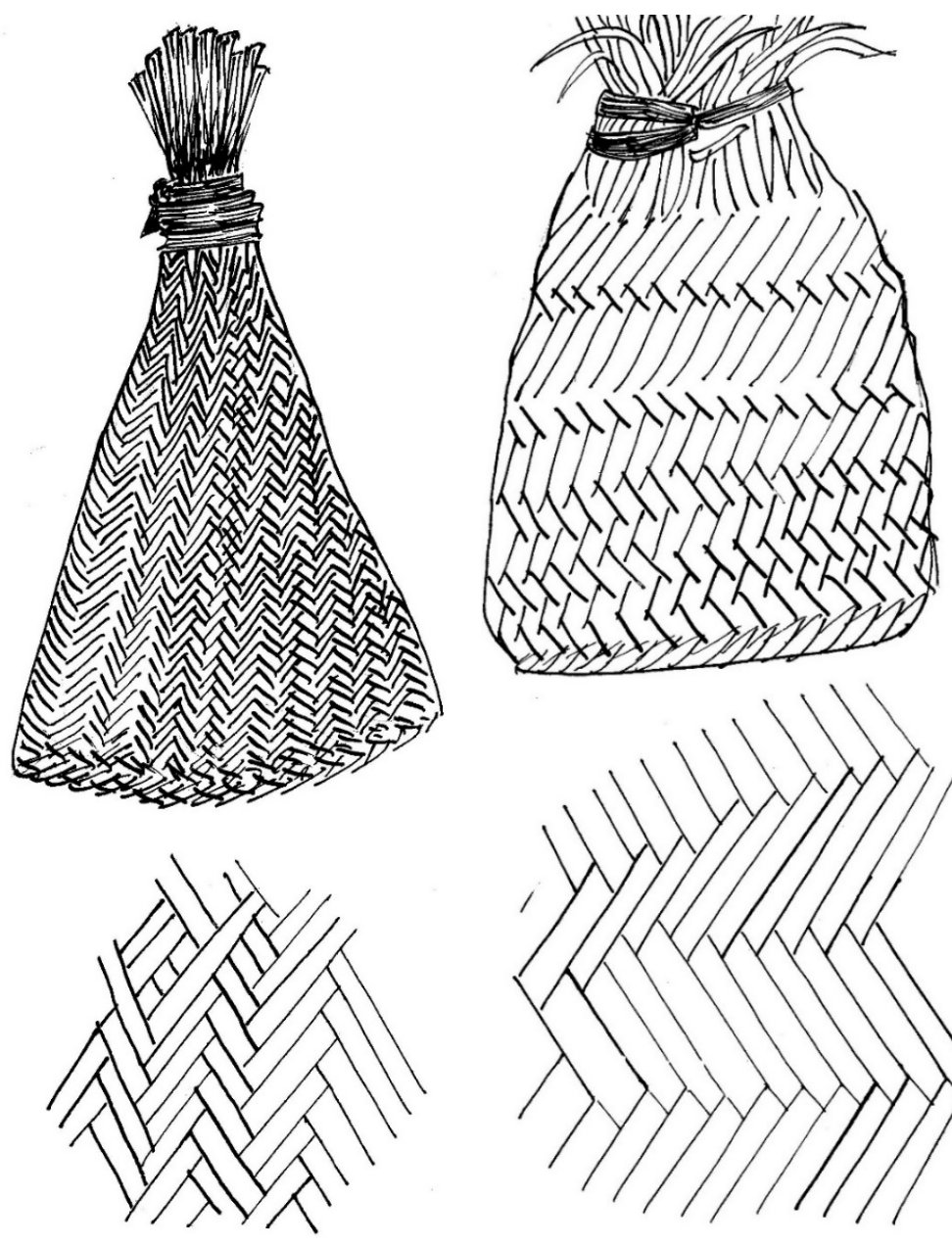

Fig. 12 Hewárontsi katsiatonkiri.

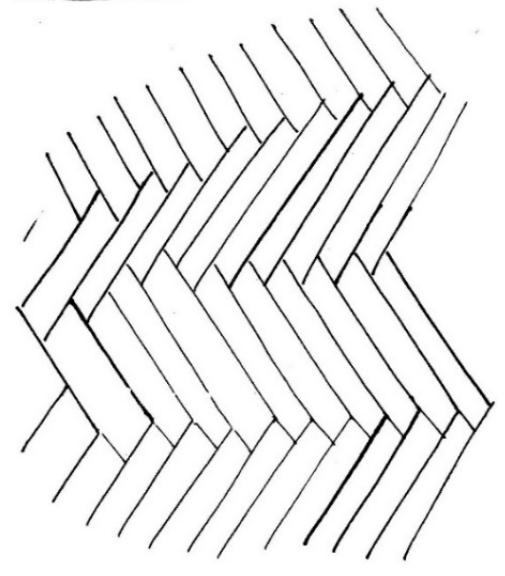

Fig. 13 Hewárontsi etsipeki.

una canasta de cavidad profunda de tejido octogonal, el cual es abierto cuando es producido con fibras de las lianas tapetsa o tsirompita y cerrado cuando el tejido es realizado con los foliolos obtenidos de la fronda de la palmera shaa (Oenocarpus, ungurave en español regional) llamada shaaki. Leroi-Gourhan, quien ha caracterizado esta técnica de tejido señala que consiste en «dos capas diagonales que se recubren sin entrelazamiento, asegurando la cohesión las hebras de una tercera capa horizontal que toma los elementos de una diagonal y saltea los de la otra» (Leroi-Gourhan, 1971: 273, nuestra traducción). Esta es clasificada por este autor como una técnica especial de cestería. Esta forma de tejido recibe también el nombre de tantentsi o thantentsi con el cual se hace referencia también a este tipo de cesta. En este caso, el borde es resuelto mediante el enrollamiento de las fibras en un anillo producido con un segmento de la liana des-

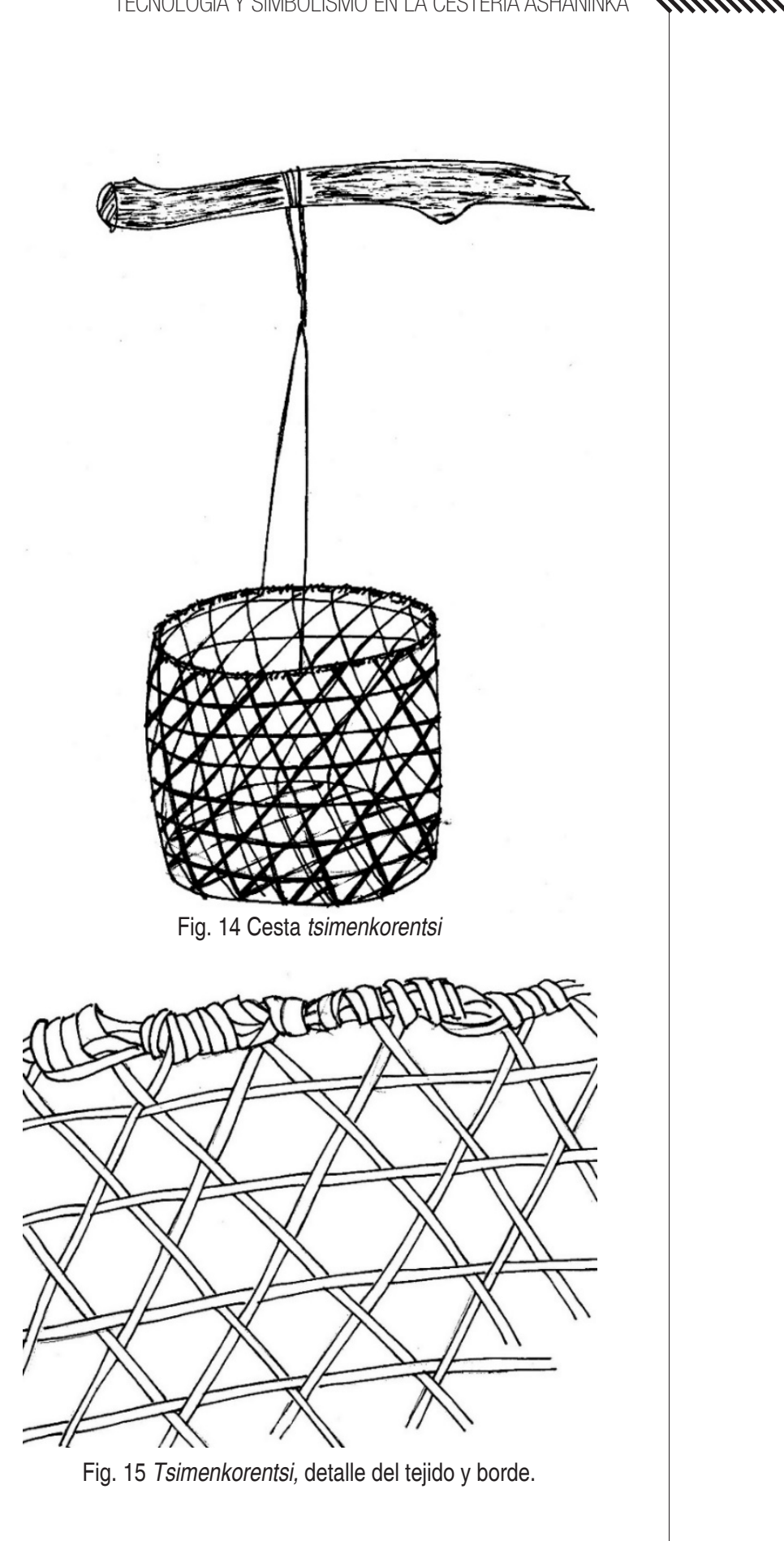

Fig. 14 Cesta tsimenkorentsi

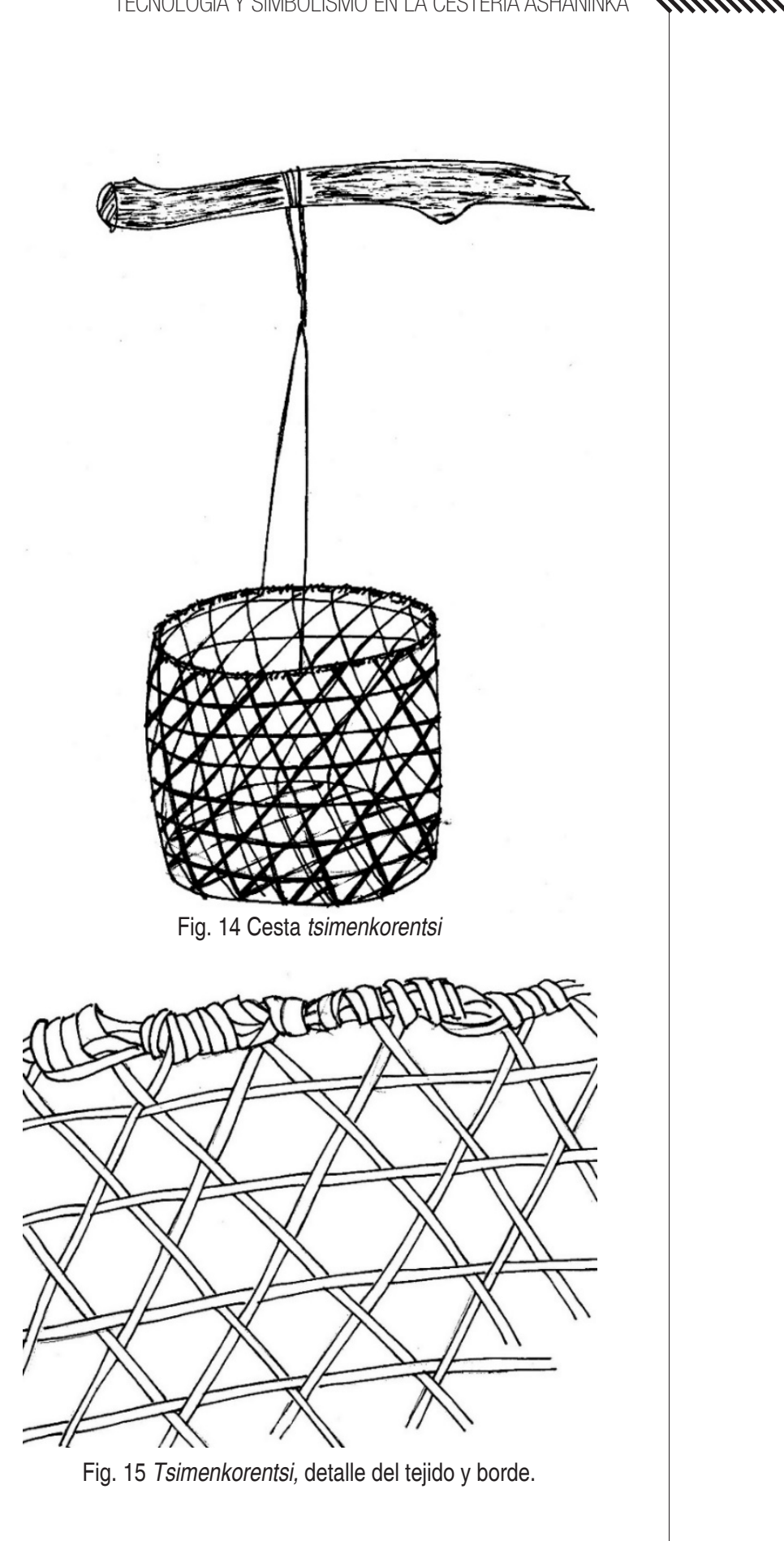

Fig. 15 Tsimenkorentsi, detalle del tejido y borde.

cortezada y sin rajar, que constituye el armazón del borde de la cesta (figura 15).

\section{Cestería y técnicas de protección y acomodación del cuerpo}

\section{Depósitos de husos, hilados y tejidos}

Los ashaninka han desarrollado un conjunto de depósitos de cestería que tienen por función depósito y 
la protección de los materiales y utensilios usados en el hilado así como en los productos del tejido y que constituyen medios de trabajo al participar indirectamente de la actividad de producción de telas.

La cesta pethananto, literalmente "elíptica» (fig. 16) recibe este nombre por la forma que presenta en la boca. Esta cesta, una variante de la kantsiri de tamaño más pequeño $(22$ por $28 \mathrm{~cm}$ ), es producida por las mujeres de las fibras obtenidas de la liana shiwitsa. Puede ser descrita como rectangular de forma achatada, de tejido recto de hebras tejidas, de armado de tipo 2 toma 2 salta llamado kaninari. Descontada la obtención y preparación del material, etapas que hemos descrito anteriormente, la fase de tejido del fondo de esta canasta tiene por primera secuencia la formación de un haz de fibras de shiwitsa. La segunda secuencia consiste en unir en posición perpendicular a dicho haz en su parte central una serie de fibras en sucesión, en su punto. Esta unión es llevada a cabo por medio de la fibra que constituirá la hebra del tejido, al evolucionar circularmente sobre dichos elementos. Con esto se obtiene la organización de los montantes del tejido. Luego la fibra, que como hemos dicho constituye la hebra del tejido es llevada por arriba y debajo de los montantes de acuerdo con el patrón de dos tomadas dos saltadas del patrón de tejido ya señalado evolucionando de manera circular alrededor de la parte central del haz inicial dando forma a las paredes. Los bordes son resueltos por enrollamiento de los montantes en anillo elíptico hecho de una sección de la liana que no ha sido separada en fibras, que constituye el armazón de la boca. Este tipo de cesta es usada por las mujeres para guardar los husos del hilado y secundariamente para atrapar peces durante la pesca con piscícidas.

La cesta tsiweta (figura 17), fabricada por las mujeres adultas con los largos y resistentes foliolos que constituyen la fronda de la palma tiroti (Astrocaryum $s p$. llamada regionalmente huicungo) que se desarrolla en el bosque primario puede ser descrita como una cesta con tapa, de forma cuadrangular (alrededor de $40 \times 55 \mathrm{~cm}$.), con abertura amplia y cavidad poco profunda, de tejido sargado tres tomadas tres saltadas. Los bordes de esta cesta, tanto del fondo como la tapa son asegurados por medio de un amarre con hilo de algodón de tipo circular, llevado a cabo con ayuda de una aguja de metal. Esta cesta es empleada por las mujeres para guardar los redondos ovillos de hilo y los usos

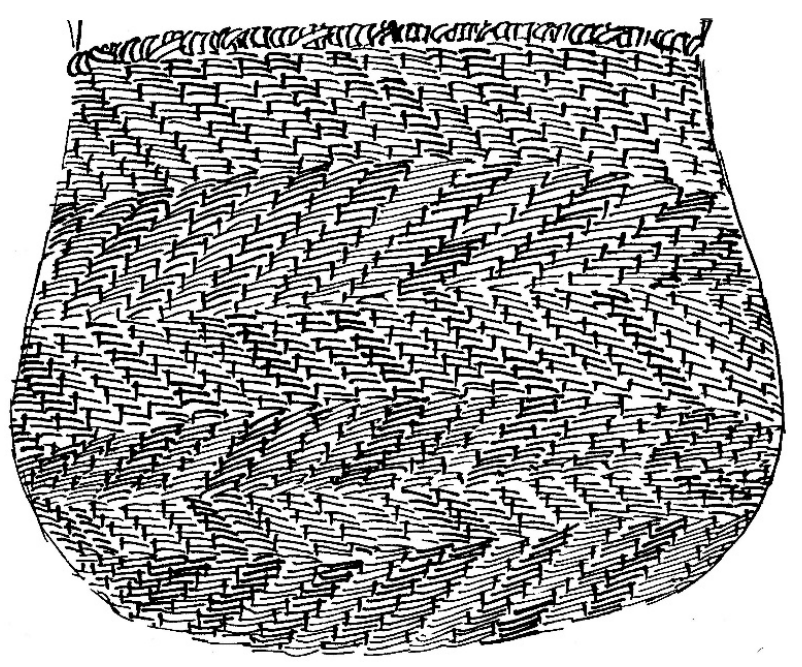

Fig. 16. Cesta pethananto

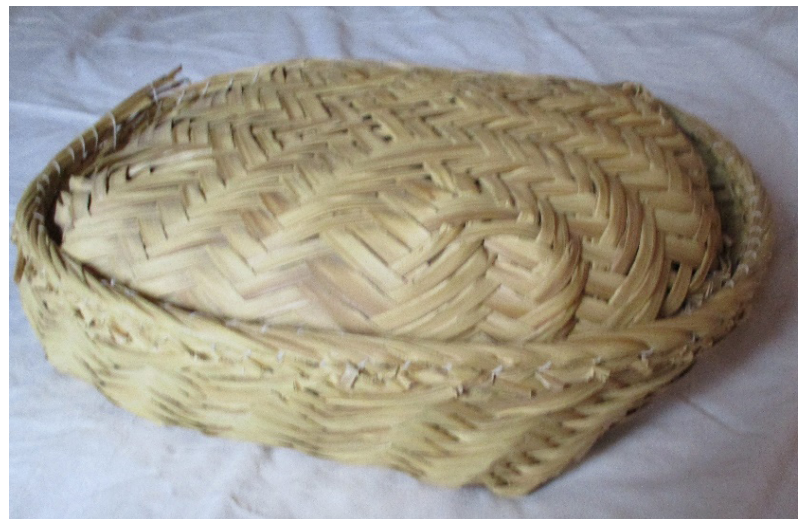

Fig.17. Cesta con tapa tsiweta.

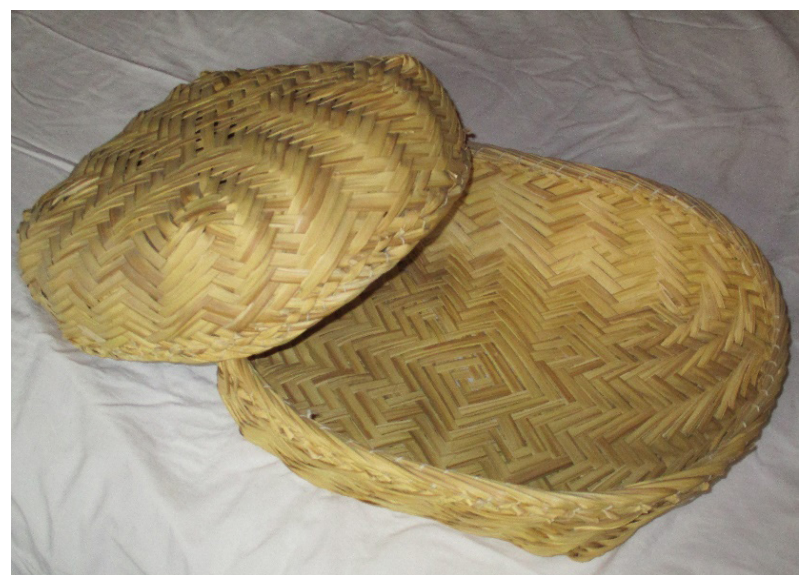

Fig. 18 Tsiweta, detalle del tejido del interior de la base.

empleados en el hilado. Ciertos ejemplares de tsiweta presentan decorados en el trenzado de la tapa que representan personajes míticos como veremos más adelante, como la araña tejedora Ametyo (figura 19). 


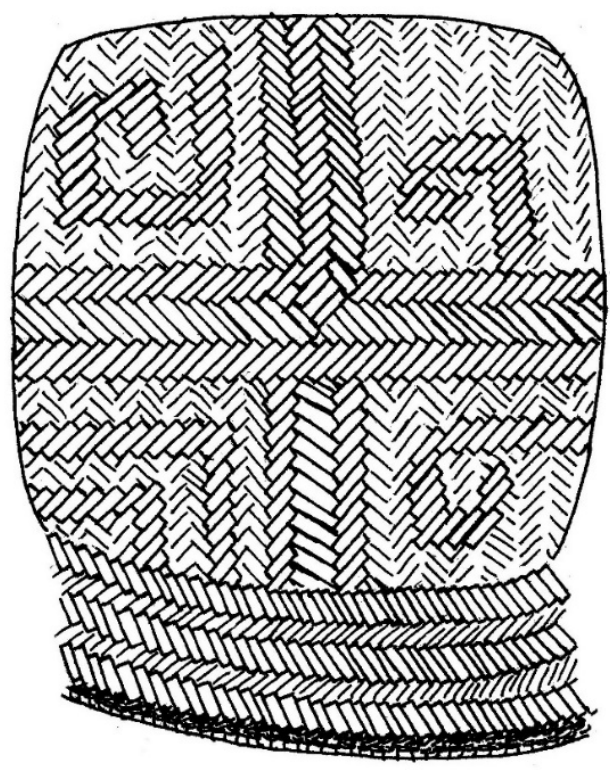

Fig.19. Detalle del tejido de la tapa de la cesta tsiweta que representa a la araña Ametyo.

Es parte indispensable de los útiles empleados por la tejedora un conjunto de pequeñas esteras de tejido 2/2 shitashintsi producidas por ella trenzando los foliolos de la fronda shaapena de la palma ungurave (Oenocarpus) o de la fronda tsiyaropena de la palma shapaja (Chamaedorea) sobre las que se coloca el algodón para el proceso de cardado el que se lleva a cabo con golpes de una varilla constituida por el pedúnculo de la flor de la cańa brava saworo llamada saworopanki endurecida al fuego o con un bastón corto llamado shintsipanki de una rama del palo balsa para aplanar los copos de algodón alistándolos para su transformación en hilo luego de haber sido retiradas las semillas con las manos (figura 20).

El tsiwó consiste en una especie de caja con tapa producida de nervaduras de hojas de caña brava, saworo (Gynerium sagittatum) aseguradas a un armazón cuadrangular de varillas del tallo rajado de esa misma planta o tramos del pedúnculo de su flor, por medio de hilos de algodón impregnados de resina vegetal tsiri del arbol tsiriki (Aspidosperma sp. según Reynel 1984: 92), formando estos un tejido de montantes y hebras enlazadas a los primeros (figuras $21 \mathrm{y}$ 22). Este tipo de depósito $(20 \mathrm{~cm}$ de altura y $30 \mathrm{de}$ lado) es el único producido por los hombres con técnicas de cestería y es utilizado por hombres y mujeres para almacenar los tejidos producidos por la esposa. Los materiales para la fabricación del tsiwó son obte-

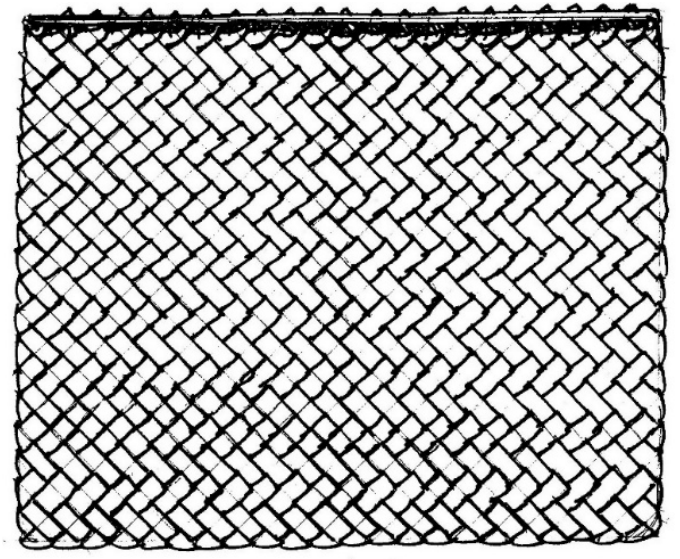

Fig. 20. Shitashintsi. Estera para el cardado del algodón.

nidos con ayuda de un machete en las orillas de los ríos en donde se pueden encontrar colonias de caña brava. Para la obtención del material son recogidas las plantas consideradas maduras, es decir, cuyas hojas presentan al tacto cierta dureza y mayor longitud.

Una primera secuencia consiste en la obtención de las nervaduras de las hojas cortándolas con un machete luego de cortar la planta por el pie. Son colocados haces de cinco hojas unas sobre otras y luego con un cuchillo es retirada la parte más delicada de estos aplicando una percusión oblicua lineal longitudinal puesta sobre ellas primero a un lado y después al otro. La operación es repetida con varios haces de folios hasta obtener una cantidad suficiente. La siguiente secuencia consiste en la obtención de las varillas para el armazón. Los mismos tallos de la caña brava saworo de los cuales fue obtenido el material para las paredes son raspados a todo lo largo en su superficie aplicando con el filo del machete con percusión oblicua lineal transversal puesta, a fin de eliminar las capas externas y los restos de los folios. Luego, estos tallos son rajados longitudinalmente en cuatro partes aplicando percusión perpendicular lineal-transversal lanzada en uno de los extremos. El material obtenido recibe el nombre de saworotonki, literalmente «hueso de la caña brava».

A continuación, con un cuchillo es retirada la pulpa interior del tallo de la parte leñosa aplicando percusión oblicua lineal longitudinal puesta obteniéndose así las varillas deseadas. Transportados los materiales a la casa, se lleva a cabo la fase de construcción de los armazones de la base y la tapa del tsiwó. Ambos armazones presentan forma rectangular si bien uno presenta un tamaño ligeramente menor 
en relación al otro, de manera que la base entra dentro de la tapa al serle colocada esta. Dada la similitud entre ambos armazones la descripción de la fabricación de uno puede valer como ejemplo para los dos casos. Se construyen dos rectángulos en base a sendas varillas de saworotonki. Dos varillas que servirán de medida para los lados son cortadas: una larga y una corta. Estas son colocadas sucesivamente a lo largo de las varillas con que se dará forma a los rectángulos.

Aplicando con el cuchillo percusión oblicua lineal-longitudinal puesta, son talladas muescas en los puntos donde termina cada medición. Empezando con la medida larga, se obtiene así una división de tres tramos largos intercalados con dos cortos en cada varilla. Luego, ambas varillas son sometidas a calentamiento indirecto por interposición del aire en los puntos en que se han realizado las muescas, al ser estas zonas acercadas al fuego. Una vez calentada, cada varilla es doblada en dichos puntos dando forma a un rectángulo. Los extremos largos de la varilla son colocados en posición paralela, siendo unidos uno al otro por medio de tres amarres circulares, dos a los extremos y uno al medio practicados con hilos de algodón impregnados en resina tsiri.

Para esto, un hilo grueso de algodón es preparado en base al hilo previamente elaborado por la mujer con ayuda del huso. El hombre se sienta en el suelo, cerca del fogón con la pierna izquierda estirada. Toma el huso de su mujer y sosteniendo el extremo del hilo enrollado en este entre los dedos pasa dos vueltas entre sus manos y el dedo pulgar de la pierna estirada. Luego, haciendo rodar los extremos entre sus palmas produce un hilo más grueso. Manteniéndolo tirante, este es frotado en una barra de resina tsiri, previamente sometida a calentamiento indirecto al ser acercada al fuego impregnándola a todo lo largo. Con este aglutinante los amarres quedan asegurados. Una vez armados los dos rectángulos se procede a la fabricación de cuatro piezas que los unirán manteniéndolos en posición paralela. Aplicando percusión oblicua lineal-longitudinal puesta, son cortadas ocho varillas de saworotonki de la misma longitud. Estas son unidas por parejas en posición paralela por medio de dos amarres circulares de hilo impregnado con la resina tsiri a los lados del punto central. Luego, los extremos de estas piezas son ensambladas en las esquinas de los rectángulos producidos en la secuencia anterior. Las uniones son aseguradas con amarres cruzados o «en equis» con hilo de algodón impregnado en tsiri. Una vez fabricados los armazones de la tapa y la base, se da inicio a la fase del tejido de las paredes del tsiwó. Para simplificar este proceso, describimos el tejido de la tapa. La primera secuencia de esta fase consiste en amarrar el centro de un hijo de algodón impregnado en tsiri con un nudo simple doble en el punto medio de cada una de las varillas dobles que unen los dos rectángulos del armazón de la tapa entre sí, estos hilos constituirán la trama del tejido.

La siguiente secuencia consiste en la colocación de los foliolos de la hoja de la caña brava que cumplirán la función de montantes. Cada foliolo es colocado de manera que sus extremos envuelven por dentro y por fuera la estructura de las paredes laterales, formando su parte central un elemento de la parte superior de la tapa. Un primer montante es colocado hacia uno de los lados menores del rectángulo. Partiendo de la parte interna del larguero que constituye uno de los lados mayores del rectángulo superior del armazón, el montante es llevado hacia el larguero paralelo del rectángulo superior del armazón donde este es doblado para volver a subir por la parte exterior del armazón al punto de partida. Llegado al punto inicial, las partes plegadas del montante son atadas una contra la otra con un nudo simple con ambos extremos del cordel atado en la secuencia anterior a una de las varillas dobles. Luego, el mismo montante es doblado sobre el armazón de la tapa pasando el extremo libre hacia el lado opuesto del armazón donde es doblado hacia abajo y al llegar al lado mayor del rectángulo inferior nuevamente hacia arriba para atar las partes plegadas una contra la otra con el cordel amarrado al larguero de la misma forma que en el caso anterior. Uno nuevo montante es colocado y tejido de la misma manera en el extremo opuesto del armazón rectangular, paralelo al anterior y así sucesivamente en los lados paralelos restantes del armazón rectangular. Los montantes son entonces colocados de manera intercalada ya en unos lados paralelos, ya en otros, dándose la figura de que de manera intercalada los de un lado van ya encima, ya debajo de los del otro lado.

El tejido va avanzando así de los lados hacia el centro. Cuando sólo queda un espacio rectangular libre en el centro de la tapa esta disposición intercalada de los montantes es cambiado por dos conjuntos de cinco montantes cada uno, que con colocados de un extremo a otro de la tapa cubriendo las aberturas 


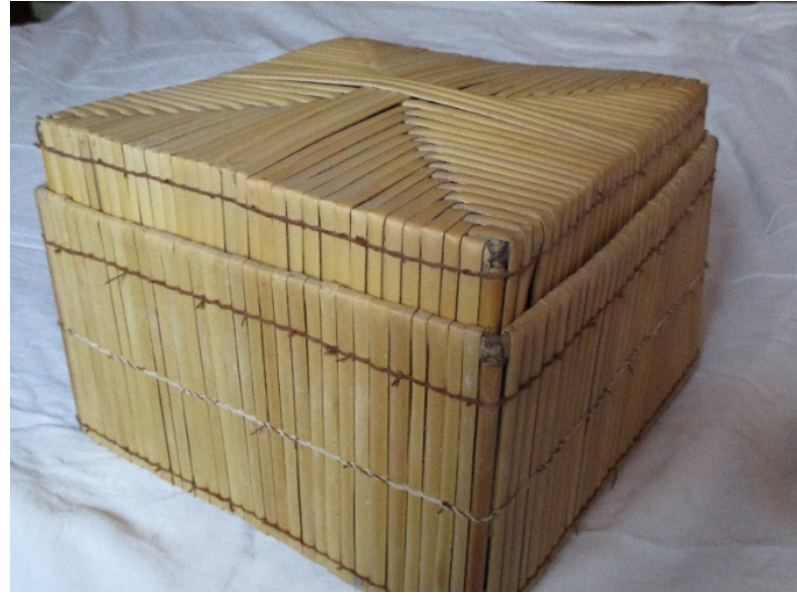

Fig. 21. Tsiwó.

restantes. Estos montantes son colocados de manera similar a los anteriores, pero sin intercalar los de un lado con los de otro. El resultado es la tapa del tsiwó tejida.

\section{Cestería y acomodación del cuerpo}

Un aspecto importante del confort en la habitación ashaninka está dado por las esteras, colocadas sobre las tarimas de madera de la palma kamona (Iriartea) rajada sobre las que las personas descansan y duermen llamadas shitashintsi. Estas son producidas por las mujeres de hojas de las palmas shaa (Oenocarpus, ungurave) o tsiyaro (Chamaedorea, huicungo) en tejido sargado (figura. 23) o en una versión de mayor tamańo de la empleada en el cardado del algodón (figura 20). Un tema a parte respecto al confort son las hamacas para bebés iyao o ikewo producidas por las mu-

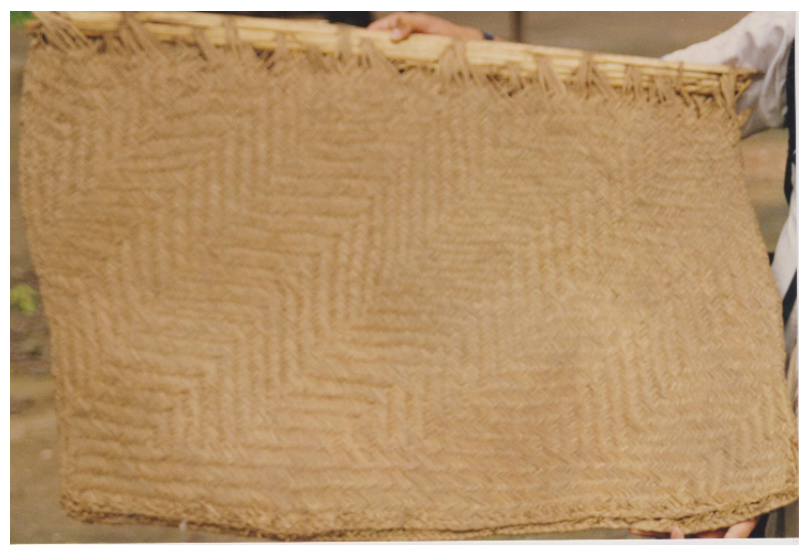

Fig. 23 Estera con tejido tipo sarga shitashintsi.

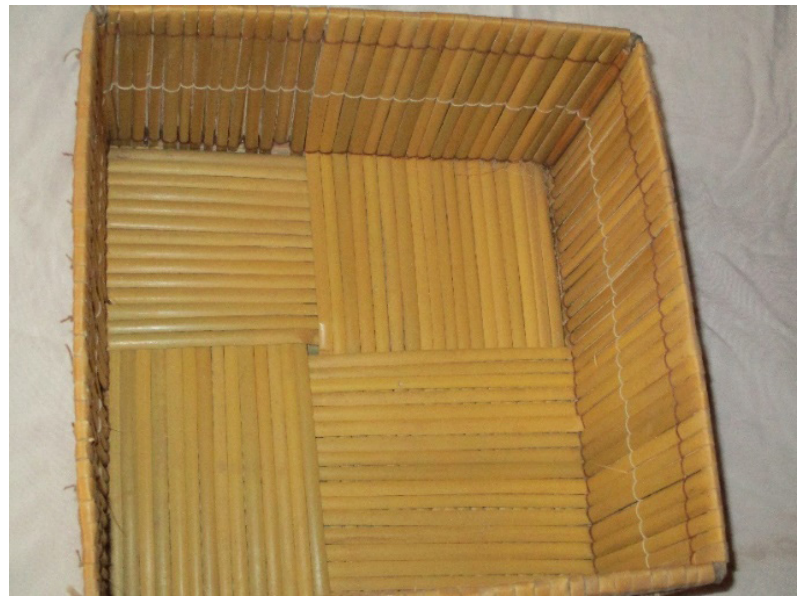

Fig. 22 Tsiwó.Detalle del tejido de la parte inferior

jeres con largas tiras de la corteza interior del árbol cetico (Cecropia). Estas sin embargo no corresponden al ámbito de las técnicas de tejido de cestería propiamente sino a las técnicas de tejido por anudamiento.

\section{Cestería y técnicas de adquisición: las trampas de pesca}

Cabe aquí señalar que ciertas formas de trampas de pesca ashaninka, participan en su producción de las técnicas de la cestería como la nasa semicilíndrica $t s i$ yanarentsi producida por los hombres y utilizada por mujeres y niños para atrapar la morralla en las quebradas (ver Rojas Zolezzi, E. 1994: 98, 202-203), y las trampas de barrera producidas por los hombres shimpere (figura 24) y tsipekirontsi (figura 25) esta última empleada en la técnica de pesca kamórentsi (ver Rojas Zolezzi, E. 1990: 154-155; 2004: 655-671). En estos casos se trata de un tejido que constituye una variante extremadamente simplificada de la cestería de tipo espiralada con hebras tejidas 1/1 (Leroi-Gourhan 1971: 274-275) en que los montantes, constituidos por pedúnculos de la flor de la cańa brava o tallos rajados de ésta como también por varas obtenidas de la madera del tallo de la palmera kamona (Iriartea) son tomados y saltados por los elementos móviles o hebras constituidos por cintas de la corteza interior de los árboles llamados shiwitsa o shiwitha de las ya citadas Annonaceae, Guatteria chlorantha y Annona sp. (Reynel et al 1990:64-65) en dos línea paralelas en las partes superiores del panel al que dan forma. 


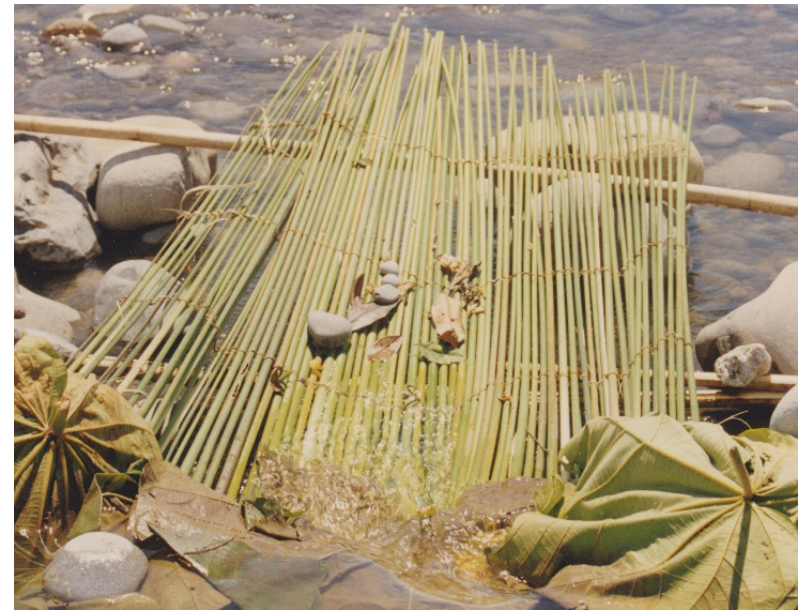

Fig. 24 Trampa de pesca shimpere en versión pequeña (Rojas Zolezzi, E. 2004).

\section{Cestería y ornamentación masculina}

Finalmente, la cestería entre los ashaninka, también tiene un lugar en la ornamentación masculina. El tocado masculino tsikententsi (figura 26) es manufacturado por los hombres en fibras obtenido del raquis de la ya citada palma tiroti (Astrocaryum sp.) (diámetro mínimo $19 \mathrm{~cm}$. máximo $24 \mathrm{~cm}$.). Las fibras, de color claro, son colocadas en forma paralela y unidas con hilo de algodón teñido de color obscuro producido por la esposa en forma de diferentes diseños. En el caso presentado estos representan la cola caudal del pez shimá (Prochilodus sp.). Al conjunto, que toma la forma de un pequeño panel plano y oblongo, se le da luego una curvatura con las manos y atado por los extremos formando un anillo. Cuatro anillos de algodón son atados a la fibra superior que conforma el panel en cuatro diferentes puntos los que son unidos por dos hilos del mismo color para evitar que este regrese a su forma original plana. En la parte superior se amarra una fibra larga de la liana seńalada la que es enrollada en espiral hasta por tres veces. La sección de esta fibra en su última vuelta es enrollada en hilo de color obscuro antes de ser atada la punta del extremo. Generalmente este tocado es portado con dos plumas rojas y azules de guacamayo insertadas hacia la parte trasera del cráneo. Una variante es producida cubriendo el panel oblongo curvado, con las púas amarillas de extremos negros del puerco espín tontori (Coendou bicolor) (Rojas Zolezzi, E 2014:157) atadas con hilo de algodón yuxtapuestas en hilera en posición vertical empleando el contraste de los colores

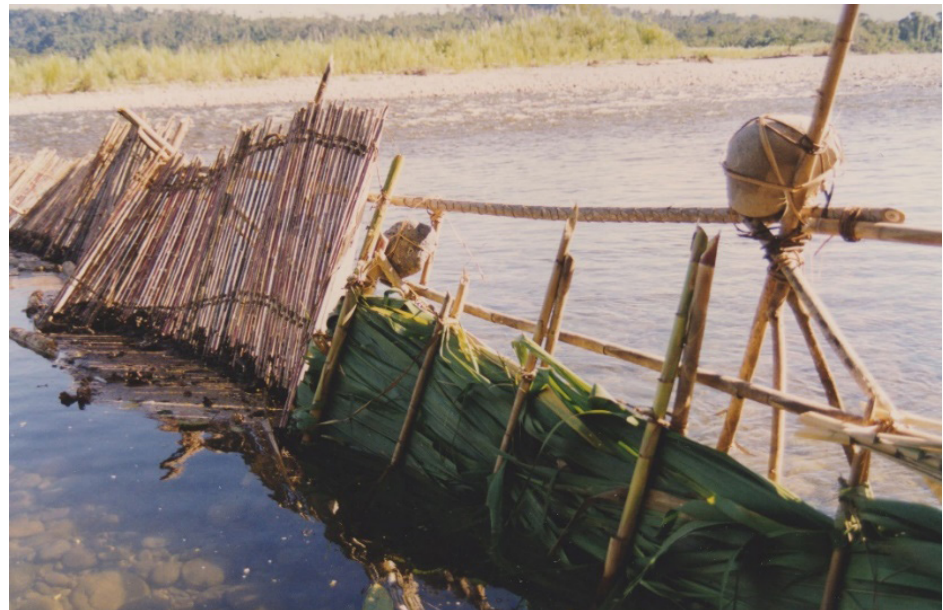

Fig. 25. Trampa de barrera tsipekirontsi (Rojas Zolezzi, E. 2004).

negro y amarillo de éstas para organizar un patrón zigzagueante (figura 27).

\section{Aspectos simbólicos de la cestería ashaninka}

En los textos de la tradición oral ashaninka, la cesta de carga kantsiri aparecen repetidamente como una extensión para usos técnicos multifuncional al cuerpo femenino. El mito registrado acerca de su origen no se refiere sin embargo a su función principal, aquella de cargar con la cosecha y los frutos silvestres recolectados, sino a la pesca de la morralla y los camarones. En este se atribuye al ave Shenkanto (no identificada) que habita en las riberas de los ríos, donde atrapa pequeños insectos en el barro, haber enseñado a la mujer la técnica del tejido de las canastas de carga kantsiri siendo considerada una entyo o cuñada (Borios 2005: 91-92, 132-134).

Respecto a la cesta con tapa tsiweta, manufacturada por la mujer y consagrada al cuidado de los husos y las bolas de hilo que ella produce con éstos, si bien no encontramos un mito sobre su origen, los aspectos simbólicos en torno a esta son abundantes. Ella constituye el opuesto simétrico a la tsiwó producida por el hombre y en la que este guarda las túnicas que le entrega su mujer y que en muchos casos serán destinadas a intercambios por los que éste obtendrá bienes manufacturados industrialmente para uso de su mujer y los miembros de la unidad doméstica pero también, eventualmente, las armas de fuego que usará como cazador y guerrero. Cabe señalar que, en el 


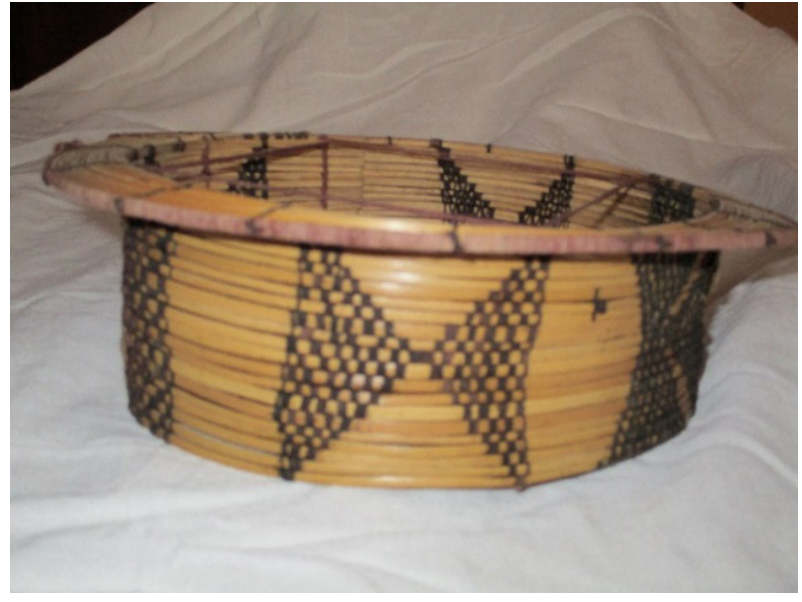

Fig. 26. Tocado masculino tsikententsi

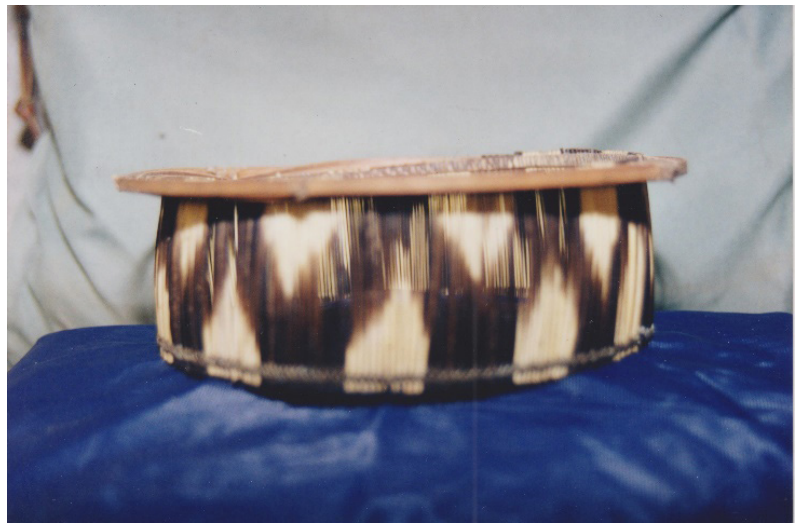

Fig. 27. Tocado masculino de púas puerco espín

tsiweta, la mujer guardará, el hilo, producto indispensable al ensamblaje de las diferentes partes constituyentes de sus flechas sin el cual éstas no podrían ser producidas. Los mitos ashaninka referidos a este tema son dos, uno referido al origen de las técnicas de caza y las flechas, y otro a las técnicas de hilado y tejido. Estos constituyen un grupo de transformaciones con textos de los cercanamente emparentados matsigenka y que resultan más explícitos respecto a ciertos detalles acerca del origen atribuido a dichas técnicas femeninas. En la tradición ashaninka, en un tiempo anterior al surgimiento de la agricultura y la vestimenta tejida, la araña Ametyo se apiada de la desnudez de la mujer y enseña a esta hilar y tejer, la que posteriormente ofrece a su esposo su primera túnica y morral. Sintiéndose humillado al no poder ser recíproco frente a los obsequios de su mujer, finalmente encuentra una solución cuando recibe de la iguana Shakota, el conocimiento de las técnicas de caza gra- cias a lo cual puede proveer a su mujer de presas por él capturadas.

La transmisión de este conocimiento se ve interrumpida cuando el hombre, en un arranque de efusividad, muestra sus flechas a su esposa. Pero la araña Ametyo no llega a transmitir el conocimiento técnico a la mujer, y se retira al ser avergonzada por una mujer que la descubre oculta entre los ovillos de hilo cuando levanta la tapa del tsiweta y la califica de arańa. El ave tanagra chenkaro (fam. Thurpidae) termina posteriormente por enseñar a la mujer estas técnicas. En los textos matsiguenga aparecen detalles que permiten entender mejor el curso de acción de los personajes: la arańa no hila propiamente, sino que devora los copos de algodón los que elimina de su cuerpo por el ombligo en forma de filamento al igual que las arañas comunes la seda. La mujer que la humilla criticando este comportamiento es su suegra, la que tilda su hilado de excremento. Es sólo posteriormente que las mujeres con gran inversión de esfuerzo, aprenden a hilar con ayuda del huso (Rojas Zolezzi, E. 1994: 115-116; Rojas Zolezzi, E. 2004: 435; Rojas Zolezzi, E. 2014:240-241; Rojas Zolezzi, M. 2017: 178-184). Sin embargo, algunos ejemplares de tsiweta son decorados con un diseño que representa a Ametyo la araña (figura 18), estableciendo una relación entre este personaje mítico y el espacio fuertemente femenino que la tradición oral atribuye haberle servido de habitación. Tenemos pues, que existe en este caso como en otros pueblos amerindios (Lévi-Strauss 1993: 164) una relación entre este personaje mítico vinculado a las técnicas de hilado y la cesta en cuestión a través de la decoración. En cuanto al tocado masculino, los diseńos que exhibe corresponden a los fosfenos o alucinaciones en forma de figuras geométricas que los ashaninka experimentan durante la ceremonia del ayahuasca kamarampi (Banisteriopsis caapi) a los que se atribuye ser los espíritus de los no humanos, principalmente presas de caza o dañinos (serpientes por ejemplo). En el caso del tocado con púas de puerco espín, es pertinente señalar que esta especie, en la época en que existía un estado de indiferenciación entre humanos y no humanos, fue parte del conjunto de guerreros - junto con la avispa y el perezoso- que intentó llevar la violencia asesina al cielo a donde se estaba retirando el sol abanconando esta «tierra de muerte» de guerra, incesto y enfermedad, escalando por la liana cósmica. 
Existe pues en este caso una asociación con la figura del guerrero. Todo ashaninka adulto hace la guerra, y el tocado masculino, en las reuniones de líderes locales es complementado por un collar ancho de semillas negras y blancas usado a la bandolera cuyo diseño zigzagueante representa una serpiente y que connota agresividad.

\section{Discusión y conclusiones}

Comparando la cestería ashaninka con la de otros casos en la cuenca amazónica podemos encontrar la amplia distribución de ciertas soluciones técnicas (O’Neale 1949) en ella lo que corresponde a su origen en los inicios de su ocupación humana (Lathrap 1970). Llama sin embargo la atención la presencia de la figura de la caja en pueblos muy distantes entre sí, como los warao del Orinoco (Wilbert 1972: 73) y los oyana de la Guyana (Roth 1921: 33) si bien en versiones flexibles, a diferencia del rígido tsiwó ashaninka el que presenta una versión muy parecida entre sus vecinos arawak los yine-piro (Farabee 1922: 61).

De hecho, resulta impresionante el enorme parecido entre esta última y la caja de lados de hojas de los Waiwai de la Guyana registrada por Roth (1921: 37). La tsiweta ashaninka parece ser una influencia de los matsiguenka del río Urubamba en los ashaninka que habría desplazado al pethananto al igual que el colador de bebida de yuca manufacturado en fibra de tiroti. Sin embargo, si bien problemas técnicos similares reciben soluciones análogas en la misma área ecológica y cultural, la impronta del estilo socialmente definido marca su carácter distintivo en cada caso.

Como en el resto de las sociedades amazónicas, las soluciones de orden técnico en el caso ashaninka, son resultado de la movilización de diferentes conocimientos etnobotánicos, etno-ecológicos y técnicos los que constituyen parte de las fuerzas de producción y las bases materiales de la construcción de los géneros en una sociedad en que este es el criterio más importante en la definición de la división del trabajo siendo con excepción de las trampas de pesca, la caja tsiwó y la ornamentación masculina, un conocimiento de mujeres. Los aspectos estéticos de algunos de estos objetos se encuentran directamente vinculados a los aspectos simbólicos que pautan dicha división del trabajo. Esto es particularmente claro en el caso del tsiweta, compartido con los cercanamente emparentados matsiguenka y los yine piro aunque entre éstos últimos sin cubierta (Farabee 1922: 55), en cuya tapa se encuentra representada la arańa Ametyo a la que se atribuye haber tejido las primeras túnicas, morrales, bandas para cargar bebés y capuchas masculinas y que definiera una de las funciones centrales del rol femenino en esta sociedad - la producción del tejido- frente al masculino subrayado por la cacería. En el caso del tocado masculino, los diseños en este representan los espíritus de los no humanos vistos en forma de fosfenos provocados por el psicotrópico ayahuasca. Si bien hombres y mujeres las perciben, son sólo los hombres quienes los comunican, aún en el caso de los tejidos de algodón producidos por las mujeres, los que se considera les son descritos por los hombres.

Esta concepción, que pone en manos de los hombres en último término aspectos simbólicos vinculados a la comunicación con los espíritus y que constituye parte de los mecanismos que les otorgan el poder sobre las mujeres, tiene sin embargo sus límites: el tsiweta, la canasta que la mujer teje y que se presenta como la contraparte del tsiwó masculino, y en el en que la mujer guarda tanto los husos como las bolas de hilo —y del que ella extrae para entregárselas a su esposo- material sin el cual su pareja masculina no podría manufacturar sus armas de cazador o guerrero, ni los ornamentos distintivos de los hombres, constituye simbólicamente el reducto último del espacio de la mujer.

\section{Agradecimientos}

Deseo expresar todo mi agradecimiento a los pobladores de las comunidades ashaninka pertenecientes a la Central Ashaninka de Río Tambo (CART) y la Federación Ashaninka del Río Ene (FARE) quienes me permitieron realizar mis observaciones etnográficas. Asimismo, a los ashaninka del río Pichis habiendo sido la información correspondiente a dicho valle expuesta anteriormente en mi tesis de Licenciatura no publicada de 1990 siendo datos a libre disposición del público. 


\section{Referencias bibliográficas}

BAER, Gerhard (1994). Cosmología y shamanismo entre los matsiguenga. Quito : ABYA-YALA.

BALfET, Hélène (1993). "Tendance et analyse des documents matériels ». Techniques et Culture 21, pp. 27-36

Borios, Stéphanie (ed.) (2005). Ikanta ishimajeita ashaninka. Los ashaninka y la pesca. Lima: IBC

Craig, Allan (1967). "Brief ethnology of the Campa Indians, eastern Peru». América Indígena, Vol. XXVII, $\mathrm{n}^{\circ} 2$, pp. 223-35

FARABEe, William Curtis (1922). Indian tribes of Eastern Peru. Papers of the Peabody Museum of American Archaeology and Ethnology. Cambridge Massachusetts: Harvard University.

FARABEe, William Curtis (1924). The central caribs. University Museum.

Godelier, Maurice (1984). L'Idéel et le matériel. Pensée, économies, sociétés. Paris : Fayard. Pp. 348

Hames, Raymond y Hames, Ilene (1976). «Ye'kwana Basketry: Its Cultural Context». Antropológica 44, pp. 3-58

Koch-Grünberg, Theodor (1910/2011). Zwei Jahre unter den Indianern reisen en Nordwest-Brasilien (1903/1905). Cambridge: Cambridge University Press.

Lathrap, Donald (1970). The Upper Amazon. London: Thames and Hudson.

Leroi-Gourhan, André (1971). L’homme et la matière. Paris : Éditions Albin Michel.

LÉvi-Strauss, Claude (1993). Regarder, écouter, lire. Paris : Librairie Plon.

Lizot, J. (1974). "Contribution à l'étude de la technologie Yanomami ». Antropológica 38 : 15-33.

Métraux, Alfred (1928). La civilisation matérielle des tribus Tupi-Guarani. Paris : Librairie Orientaliste Paul Geuthner.

Nordenskïold, E. y Schlosser, I. (1924). Forschwigen und abentever en Südamerika. Strecker und Schröder.

O’Neale, Lila M. (1949). "Basketry». En Steward, J. (ed.) Handbook of South American Indians. Washington: Smithsonian Institution Bureau of American Ethnology Bulletin 143, Vol. 5, pp. 69-96

Reynel, Carlos (1984). "Árboles en lengua Campa Ashaninka». Boletín de Lima, $\mathrm{N}^{\circ}$ 36: 85-96
Reynel, C. Albán, J., León, J. Díaz, J. (1990). Etnobotánica Campa Ashaninka con especial referencia a las especies del bosque secundario. Lima: Universidad Nacional Agraria La Molina- Facultad de Ciencias Forestales.

Rojas Zolezzi, Enrique (1990). Pachákama, Inka y el origen de las herramientas de acero. Dones divinos y reemplazo tecnológico en un contexto de subordinación económica e intercambio desigual. El caso de los Campa Ashaninka de la Selva Central (Tesis de Licenciatura, Pontificia Universidad Católica del Perú, Lima, Perú).

Rojas Zolezzi, Enrique (1994). Los Ashaninka, un pueblo tras el bosque. Lima: Fondo Editorial de la Pontificia Universidad Católica del Perú.

Rojas Zolezzi, Enrique (1999). "Aspectos técnicos y simbólicos del hilado y el tejido entre los asháninka». Anthropológica 17, pp. 117-134

Rojas Zolezzi, Enrique (2004). Mythes de la création du monde, représentations du gibier et des plantes cultivées et définition de l'ordre social traditionnel chez les campa ashaninka de l'orient péruvienne (Tesis doctoral, École des Hautes Études en Sciences Sociales, París, Francia).

Rojas Zolezzi, Martha (2017). Tejiendo la identidad. Mitología y estética entre los Matsiguenka del Bajo Urubamba. Lima: Editorial Horizonte.

Roтн, William. E. (1921). The Arts, Crafts and Customs of the Guiana Indians. Washington D.C.: Bureau of American Ethnology.

Tessmann, Gunther (1930/1999). Los indigenas del Perú nororiental. Quito: ABYA-YALA.

WeIss, Gerald (1975). Campa Cosmology. The World of a forest tribe in South America. New York: Anthropological Papers of the Museum of Natural History.

Weiss, Gerald (2005). «Campa ribereños». En Santos, F. y Barclay, F. (eds.) Guia Etnográfica de la Alta Amazonia. Lima: IFEA-Smithsonian Tropical Research Institute, Vol. 5, pp. 1-74

Wilbert, Johannes (1972). Survivors of El Dorado. Four Indian cultures of South America. New York: Praeger Publishers.

Wilbert, Johannes (1975). Warao Basketry: Form and Function. Occasional Papers of the Museum of Cultural History. Los Angeles: University of California Press. 